\title{
Explaining the Saving Behavior of Households' in Ethiopia, Africa
}

\author{
Eric Asare ${ }^{1}$, Eduardo Segarra ${ }^{2}$, Nakakeeto Gertrude ${ }^{3}$, Fafanyo Asiseh ${ }^{4}$ \\ ${ }^{1}$ Texas Tech University, Box 42132, Lubbock, TX 79409-213, USA \\ ${ }^{2}$ Texas Tech University, Agricultural Sciences 205-E Lubbock, TX 79409-213, USA \\ ${ }^{3}$ Texas Tech Univ., Box 42132, Lubbock, TX 79409, USA \\ ${ }^{4}$ Depart. Of Econs., College of Bus. \& Econs, 1601 Merrick Hall, Greensboro, NC 27411, USA \\ Correspondence: Eric Asare, Texas Tech University, Box 42132, Lubbock, TX 79409-213, USA.
}

Received: January 12, 2018

doi:10.11114/aef.v5i2.2923

\author{
Accepted: February 9, $2018 \quad$ Available online: February 22, 2018 \\ URL: https://doi.org/10.11114/aef.v5i2.2923
}

\begin{abstract}
Savings have been shown to have a positive impact on economic growth at the macroeconomic level. But, the micro-level analysis of households' savings behavior is limited, especially in Sub-Saharan African economies. This study contributes to the understanding of the savings behavior of households in Africa, by modeling the savings behavior of households' in Ethiopia with the two-part model. The results of the study reveal that number of extension contacts and access to market information have significant positive effects on the likelihood that a household would save. Moreover, land holdings (bad production season last year) have significant positive (adverse) impact on the expected amount of money a household would save. Based on the results of this study, policies are recommended to increase savings in Ethiopia.
\end{abstract}

Keywords: households' savings, Africa, economic growth, Ethiopia, two-part model

\section{Introduction}

Theoretically, higher savings could have a positive effect on economic growth (Lucas, 1988; Romer, 1986; Solow, 1956). Also, empirical studies show that savings lead to higher investments, and ultimately to higher economic growth (Odhiambo, 2009). For instance, in Congo, sub-Saharan Africa, increased savings have had a positive effect on economic growth (Anoruo \& Ahmad, 2001). From the preceding, savings can be an essential tool for economic growth, and could ultimately lead to poverty reduction in many impoverished regions of the world, in particular, Sub-Saharan Africa (Quartey, 2008). Unfortunately, Africa has the lowest savings rate (Deaton, 2005; World-Bank, 2017). According to Aryeetey and Udry (2000), Africa has shown consistent declines in savings for the last three decades. It has resulted in slow growth in African economies over the period (World Bank, 1994).

Savings in Figure 1 is defined as gross national income less total consumption, plus net transfers (World-Bank, 2017). Why does Sub-Saharan African countries have the lowest savings rate in the world? This fundamental question is yet to be thoroughly investigated because many of the studies on savings in developing countries have focused on Asia and Latin America (Odhiambo, 2009). Also, the few studies on African economies have tended to be at the macroeconomic level, which makes it difficult to learn about the actual savings behavior of economic units (households) at the micro-level.

The investigation into the saving behavior of households is critical because savings mobilization and the resulting capital accumulation start from individual members of society (Schmidt-Hebbel, Webb, \& Corsetti, 1992). The understanding of the saving behavior of individuals in an economy could help economic policy decision-makers of African countries, in particular, to design effective policies to increase saving rates. This study contributes to the limited literature on the saving behavior of households in Africa, by addressing this research question: what are the critical variables that could affect the amount of savings of households in Africa, in particular, Ethiopia? Subsequently, the objective of this study is to estimate the magnitude of the effects of the factors that could affect the level of savings in an African household. 


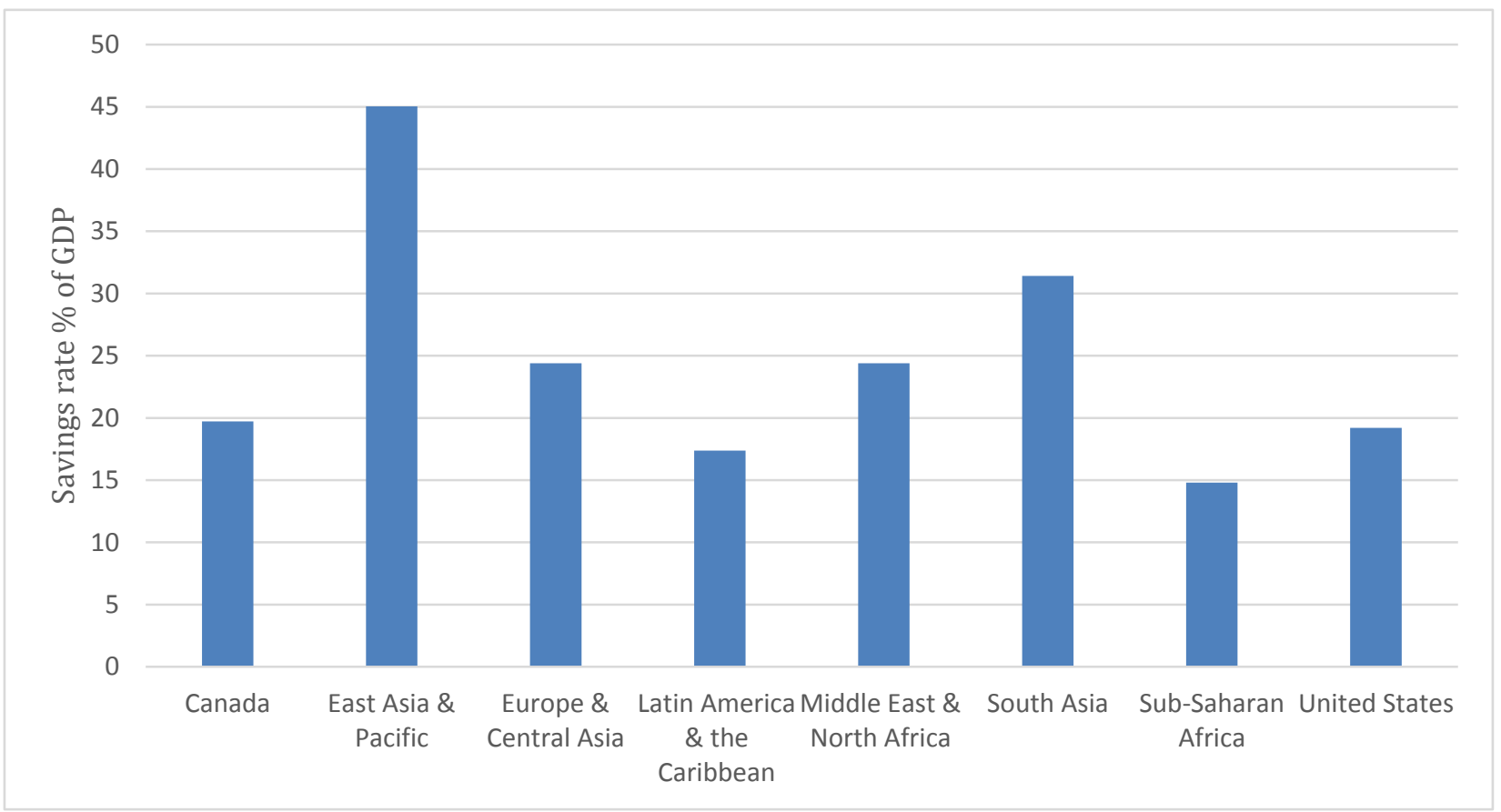

Figure 1. Savings rate a percentage of GDP across regional-group of countries $s$ in the world (Data source: The World Bank, 2017)

This study uses Ethiopia as a case study because it is one of the poorest countries in Africa. In this country, about 33.5 percent (2011 estimate) of the population live on US\$1. 9 per day (World-Bank, 2016). Again, characteristic of most developing countries, Ethiopia has an agrarian economy where agriculture contributes about 41 percent of the country's total GDP of approximately US\$61.54 billion (World-Bank, 2016).

Also. Available data from the World-Bank (2017) shows that the savings rate as a percentage of GDP for Ethiopia declined between 2011 and 2012 by approximately 6 percent. Understanding the saving behavior of households in such a country could help policymakers design appropriate policies to shore up savings in the economy and similar economies, and potentially enhance their economic growth.

\subsection{Background}

People save for many reasons. Keynes (1936) lists eight reasons why people save: a) "to build-up a reserve against unforeseen contingencies", b) "to provide for an anticipated future relationship between the income and the needs of the individual", c) "to enjoy interest and appreciation", d) "to enjoy a sense of independence and the power to do things, though without a clear idea or definite intention of specific action", e)"to enjoy a gradually increasing expenditure", f) to secure a masse de manoeuvre to carry out speculative or business projects", g) to satisfy pure miserliness, that is unreasonable but insistent inhibitions against acts of expenditure as such", and h) to bequeath a fortune". Moreover, it is expected that they would be heterogeneity with regards to the savings behavior of people in different socioeconomic or demographic classes (Browning and Lusardi, 1996). For instance, compared to households in developed nations, those in developing countries are less wealthy, more likely to engage in agriculture and more likely to have uncertain sources of income (Deaton, 1989). Therefore, the savings and consumption behavior of households from the Africa and developed and wealthy countries would be different.

According to Browning and Lusardi (1996), the theory of savings is primarily derived from the theory of consumption, since savings is a what is left of income after meeting current consumption needs. There are many macroeconomic models that have been developed to explain savings. One model that has gained much recognition and acceptance is the life cycle-permanent income model, because it treats consumption (savings) decisions as an intertemporal allocation problem (Attanasio, 1999). According to Hubbard (1994), most research on savings, wealth and consumption have been built on the life-cycle hypothesis. Mainly, the model predicts that households accumulate savings for retirements (Hubbard, 1994). The model puts a micro-foundation on consumption/savings models, rather than the Keynesian models that treats it as a function of income (Attanasio, 1999). Micro-foundations of macroeconomic models have been recognized as an insightful way of modeling macroeconomic phenomenon (Bénassy, 2011).

However, the life-cycle model is not able to sufficiently deal with uncertain environments and the complexity that dynamic problems of consumption/savings introduce into the model (Hubbard, 1994; Attanasio, 1999). Several models 
have been proposed to refine the life-cycle hypothesis to overcome the limitations in the model. According to Attanasio (1999), some of the models that have improved the life cycle-permanent income model are: a) the permanent income model - it allows for intertemporal separable, quadratic preferences, and uncertainty; b) the Euler equation model - it allows for the explicit and rigorous treatment of uncertainty. Other models are the standard addictive model (it does not assume a quadratic utility function, but an inter-temporal additive utility functions). See Attanasio (1999) and Browning and Lusardi (1996) for detailed descriptions of the above models. According to Collins (1991), the life-cycle hypothesis does not perform well for developing countries, including Africa. In her study, among others, she found out that household savings are less sensitive to changes in income for developing countries.

Mainly, intertemporal utility maximization has become the standard model of household's consumption/savings behavior at the microeconomic level (Deaton, 1989). Deaton (1992) proposed a simple model based a "rule of thumb" to explain household savings in developing countries. In their model, households would save when their income is above a threshold, say y units of a currency, and dis-save otherwise. Aryeetey \& Udry (2000) reports that the above rule of explaining savings might not work in developing countries because savings is mainly determined by the variance of income (not the absolute amount) and the availability of credit markets. Other models, such as the buffer stock savings model and the intertemporal asset portfolio allocation model, have been proposed to explain savings (Aryeetey \& Udry, 2000; Jappelli, 2008).

\subsection{Statement of Hypothesis}

Land holdings (LANDHOLDING) and number of livestock owned (LIVESTOCK) are expected to have positive effects on the probability that a household will save and also the expected amount saved. These variables are measures of wealth. It has been shown that the wealth of an economic unit has positive impacts on household savings (Ahmad, Atiq, Alam, \& Butt, 2006; Schmidt-Hebbel et al., 1992).

Illiteracy is expected to have a negative correlation with the probability that a household will save and also the expected amount saved. It is because non-educated members of the household do most likely not have access to better employment opportunities. On the contrary, it has been shown that education has a positive effect on household savings (Teshome, Kassa, Emana, \& Haji, 2013).

The number of farm-gate retailers available to the household (FG_RETAILERS) and access to market information (MKTINFO) are expected to have positive effects on the probability that a household will save and also the expected amount saved. Market information can enable households to sell or buy commodities at the right prices. Also, the number of retailers who buy at the farm gate is a proxy for market access for household farm products.

The number of extension contacts (EXTENSION) is expected to have positive effects on the probability that a household will save and also the expected amount saved. The information the extension agents provide could enable producers to increase the quality and quantity of their farm products, holding all other factors constant. Teshome et al. (2013) have shown that contacts with extension officers have a significant influence on households' savings in Ethiopia.

Bad farming season in the previous year (BAD_FSEASON) is expected to have an adverse effect on the probability that a household will save and also the expected amount saved. A bad production season is more likely to have a negative impact on a farmers' income. Again, a bad production season might cause prices of goods and services to increase, primarily when food shortages occur; this could negatively affect the amount non-agricultural producers might save. For agricultural producers, it is assumed that the gain in farm income through price appreciation might not be enough to offset the loss in the quantity and quality of farm outputs. Overall, it is expected that the producers will be affected negatively by a bad production season.

Total food expenditure (TOL_FEXP) of the household is expected to have a negative effect on the probability that a household will save and also the expected amount saved. This is because, given a fixed budget, total food expenditure is inversely correlated with savings. Following the same logic above, dependency ratio (DEP_RATIO) is expected to have a negative effect on the probability that a household will save and also the expected amount saved. The more dependents there are in a household, the higher the amount that might be spent on food. It has been shown in other studies that dependency ratio has a negative correlation with savings (Kibet, Mutai, Ouma, Ouma, \& Owuor, 2009; Leff, 1969; Schmidt-Hebbel et al., 1992).

Households with a male head (HHHEAD_MALE) is expected to have a positive effect on the probability that a household will save and also the expected amount saved. This is because men, mostly head most households in Africa; men are more likely to be those making the decisions on behalf of the household. Again, male household heads are more likely to be educated and have access to more employment opportunities.

Married and living with a spouse (MARRIED) is expected to have positive effects on the probability that a household will save and also the expected amount saved. It has been documented by Grinstein-Weiss et al. (2006) that married couples on the average save more than unmarried people. 


\section{Area Description and Data Collection}

This study uses a survey of Ethiopian rural households conducted during 2009-2010, in four Ethiopian regions, namely Tigray, Amhara, Oromia, and Southern Nations, Nationalities, and People's Region (SNNPR). The survey was conducted jointly by the International Maize and Wheat Improvement Center (CIMMYT) and the Ethiopian Institute of Agricultural Research (EIAR). A stratified random sampling strategy was used where strata are randomly selected woredas (districts) of high, medium and low maize yield potential. The resulting data are nationally representative. A total of 1,396 farm households from 30 woredas was surveyed; of these, 1,359 grow maize on 2,496 plots (46.4\% households own only a single maize plot). Apart from crop production information, information on household socioeconomic characteristics was also collected. Finally, a total sample of 441 households was used in the analysis, after respondents with missing information on the variables in the model, especially the dependent variable, were deleted.

\section{Methods and Techniques}

\subsection{Econometric Model}

The primary goal of this study is to explain the behavior of Ethiopian households with regards to the amounts they saved. The overall decision to save by a household is assumed to be a combined result of two stochastic processes, which may or may not be correlated. These decisions are believed to be made by the household head on behalf of the entire household. The first process is whether or not to participate in the saving activity, also called the participation process; the second is the amount to save given that a household decides to save, also called the intensity process. This section describes the procedures that are followed to ensure that the estimated parameters underlying the above stochastic processes are unbiased and consistent, and can be used to make reliable inferences about household saving behavior in Ethiopia.

Forty-one percent (18 households) in this study have no savings. It is possible that ignoring them in this study could cause the conclusions drawn from the modeling of the savings behavior of households in Ethiopia to be unreliable. According to Wooldridge (2010), zero observations could reflect actual outcomes arising from the maximization of economic problems facing rational economic agents. Ignoring such households in the model estimation stage might result in self-selection bias and consequently inconsistent parameter estimates (Cameron \& Trivedi, 2005; Wooldridge, 2010).

The two-part model is estimated to explain Ethiopian households' savings behavior, to account for households with zero savings. Asare and Segarra (2017) used this method to explain individual's behavior concerning students loan acquisition in the U.S.A. Unlike the Heckman's selection model, it does not require the participation and intensity stochastic processes to be correlated Cameron and Trivedi (2005). However, a Heckman's selection model is estimated to check the robustness of the estimated two-part model parameters. The Heckman's selection model adds the Inverse Mills ratio (ratio of predicted probability density function to the cumulative density function, all from the estimated participation model) as an additional regressor; but the two-part model does not by following Belotti et al (2015). The two-part model was originally developed by Craig (1971). This study models the savings behavior of Ethiopian households by following the two-part model framework of Belotti et al. (2015).

Let $L^{*}$ be a latent decision variable, observable to the individual decision maker only. This decision process compares the expected utility he/she derives from saving $\left(E\left(U_{s}\right)\right)$ and not saving $\left(E\left(U_{n s}\right)\right)$. According to the random utility model (Cameron and Trivedi, 2005), the individual will save only when the expected utility from saving is greater than that from not saving. Therefore, the probability that an individual might save (which is a function of his/her socioeconomic and demographic characteristics), also called the participation model, is:

$$
\mathrm{P}\left(\mathrm{s}_{i}=1 \mid z^{h}\right)=P\left(E\left(U_{s}\right)-E\left(U_{n s}\right)>0\right)=\Phi\left(z^{h^{\prime}} \alpha\right)
$$

where $\mathrm{P}($.$) is a probability operator, \mathrm{s}_{i}$ is a dummy variable which takes a value 1 if household did save and 0 otherwise, $z^{h}$ is a vector of households' socioeconomic and demographic factors (defined in Table 1), $\Phi($.$) is a$ cumulative normal distribution function, and $\alpha$ is a vector of parameters associated with $z^{h}$ in the participation model.

In addition, the model for positive outcomes (also called the intensity model) can be represented as: $E\left(s_{i} \mid s_{i}>0, z^{h}\right)=$ $g\left(z^{h^{\prime}} \beta\right)$. For the entire sample (those with positive or zero observations), the likelihood influence for an observation and the corresponding log-likelihood function are expressed as equations 2 and 3, respectively, below:

$$
\begin{gathered}
\emptyset\left(\mathrm{s}_{i}\right)=\left\{1-\Phi\left(z^{h^{\prime}} \alpha\right)\right\}^{i(i=0)} *\left\{\Phi\left(z^{h^{\prime}} \alpha\right) * g\left(z^{h^{\prime}} \beta\right)\right\}^{i\left(s_{i}=0\right)} \\
\ln \left\{\varnothing\left(\mathrm{s}_{i}\right)\right\}=i(i=0) \ln \left\{1-\Phi\left(z^{h^{\prime}} \alpha\right)\right\}+i\left(s_{i}=0\right)\left[\ln \left[\left\{\Phi\left(z^{h^{\prime}} \alpha\right)\right\}+\ln \left\{g\left(z^{h^{\prime}} \beta\right)\right\}\right]\right.
\end{gathered}
$$


where $\mathrm{i}($.$) is an indicator function, \ln ($.$) is the natural logarithm operator, g\left(z^{h^{\prime}} \beta\right)$ is a density function for positive saving outcomes, $\beta$ is a vector of parameters associated with $z^{h}$ in the intensity model, $\widehat{\alpha}$ is the estimated parameters from the participation model. The elements of households' socioeconomic and demographic variables in vector $z^{h}$ are defined in Table 1.

Table 1. Variable definitions and hypotheses

\begin{tabular}{|c|c|c|c|}
\hline \multirow[b]{2}{*}{ Variable } & \multirow[b]{2}{*}{ Definition } & \multicolumn{2}{|c|}{ Hypothesis } \\
\hline & & ${ }^{\text {a}}$ Participation & ${ }^{\mathrm{b}}$ Intensity \\
\hline LANDHOLDING & Total land holdings in Kirr & + & + \\
\hline LIVESTOCK & Total number of livestock owned & + & + \\
\hline EXTENSION & Number of extension contacts in & + & + \\
\hline MKTINFO & $\begin{array}{l}\text { Access to market information; equals } 1 \text { if household has } \\
\text { access to market information and } 0 \text { otherwise }\end{array}$ & + & + \\
\hline FG_RETAILERS & Number of retailers who buy at the farm-gate & + & + \\
\hline BAD_FSEASON & $\begin{array}{l}\text { Bad farming season previous year; equals } 1 \text { if information } \\
\text { true for household and } 0 \text { otherwise }\end{array}$ & - & - \\
\hline ILLITERACY & $\begin{array}{l}\text { Illiteracy; equals } 1 \text { if had no formal education and } 0 \\
\text { otherwise }\end{array}$ & - & - \\
\hline DEP_RATIO & $\begin{array}{l}\text { Dependency ratio, the ratio of the sum of household } \\
\text { members below } 15 \text { years and } 65 \text { years to the sum of } \\
\text { household members between } 16-64 \text { years }\end{array}$ & - & - \\
\hline MARRIED & $\begin{array}{l}\text { Married and living with spouse; equals } 1 \text { if true and } 0 \\
\text { Otherwise }\end{array}$ & $+/-$ & $+/-$ \\
\hline HHHEAD_MALE & $\begin{array}{l}\text { Household head; equals } 1 \text { if household head is male and } 0 \\
\text { otherwise }\end{array}$ & + & + \\
\hline TOL_FEXP & Total food expenditure & + & + \\
\hline
\end{tabular}

${ }^{a}$ Participation is the first-stage participation model, whose dependent variable is a binary variable (it equals 1 if the household saves and 0 otherwise).

${ }^{\mathrm{b}}$ Intensity is the second-stage intensity model, whose dependent variable is the natural logarithm of the amount saved in Ethiopian Birr (1 Ethiopian Birr equals 0.036 US\$, January 5, 2018).

Note from equation 3 that the parameters $(\alpha \& \beta)$ are additively separable for each observation. Therefore, the models for the participation model and the intensity models can be estimated separately (Belotti et al. 2015). The participation model will be estimated with a probit model and the intensity model with an ordinary least square estimator (OLS). The dependent variable in the intensity model is natural $\log$ of positive saving outcomes for each observation. The dependent variable for the participation model is a dummy, which equals 1 if household saved and 0 otherwise. The variables in Table 1 are the independent variables in both the participation and intensity models. They are all expected to be exogenous, including total food expenditure. Total food expenditure is the sum-product of consumable goods and services and their respective prices. Contemporaneous savings is the residual or what is left of income after meeting current consumption needs. This study, does not expect a simultaneous causation between savings and total expenditure, albeit comtemporaneously. The two models are explicitly defined mathematically as:

$$
\begin{gathered}
s_{i}=Z^{h^{\prime}}{ }_{i} \alpha+\varepsilon_{i}, \varepsilon_{i} \sim N(0,1) \\
\ln \left(\mathrm{s}_{i} \mid \mathrm{s}_{i}>0\right)=Z^{h^{\prime}}{ }_{i} \beta+u_{i}, u_{i} \sim N(0,1)
\end{gathered}
$$

Where all the variables are already defined. $\varepsilon_{i}$ and $u_{i}$ are stochastic error terms assumed to me normally distributed with an expected value of 0 and a constant variance 1 .

Both models are estimated with the "twopm" package in STATA and developed by Belotti et al. (2015). To obtain the marginal effects of the variables on the expected amount a household saves (given that a household saves) the dependent variable in equation 2 will be retransformed back to the original variable, y. It is necessary for the 'twopm' margins routine to work. The marginal effects of the variables in the participation model, probit model, are calculated using the margins post-probit routine in STATA 14. The marginal effects of the discrete explanatory variables in the participation model, show the change in the probability of saving for a change in the variable from 0 to 1 . In the case of a continuous explanatory variable, the marginal effect shows the change in the probability of adoption for a unit change in the covariate. In the case of the intensity model, the marginal impact of a discrete variable shows the change in the expected amount saved for a change in the explanatory variable from 0 to1. For a continuous variable, the marginal 
effect shows the change in the expected amount saved for a unit change in the variable. All the marginal effects are interpreted conditional on holding all other factors constant.

\section{Results and Discussion}

\subsection{Descriptive Statistics Results}

Land holdings, the number of livestock owned, the number of extension contacts, and the total food expenditure are on the average significantly higher for households that save than those that do not (Table 2).

Table 2. Summary statistics and t-Test results

\begin{tabular}{|c|c|c|c|}
\hline Variable & $\begin{array}{c}\text { Savings }=0 \\
\text { MEAN }\end{array}$ & $\begin{array}{c}\text { Savings >0 } \\
\text { MEAN }\end{array}$ & t-TEST \\
\hline LANDHOLDING & $\begin{array}{c}7.02 \\
(1.38)\end{array}$ & $\begin{array}{c}9.73 \\
(0.42)\end{array}$ & $-1.88^{*}$ \\
\hline LIVESTOCK & $\begin{array}{c}0.89 \\
(0.28)\end{array}$ & $\begin{array}{l}1.74 \\
(0.14)\end{array}$ & $-2.73 * * *$ \\
\hline EXTENSION & $\begin{array}{c}1.5 \\
(0.6)\end{array}$ & $\begin{array}{c}3.31 \\
(0.22)\end{array}$ & $-2.83 * * *$ \\
\hline MKTINFO & $\begin{array}{c}0.39 \\
(0.12)\end{array}$ & $\begin{array}{c}0.8 \\
(0.02)\end{array}$ & $-3.46 * * *$ \\
\hline FG_RETAILERS & $\begin{array}{c}0.17 \\
(0.12)\end{array}$ & $\begin{array}{c}0.1 \\
(0.05)\end{array}$ & 0.27 \\
\hline BAD_FSEASON & $\begin{array}{c}0.28 \\
(0.11)\end{array}$ & $\begin{array}{c}0.14 \\
(0.02)\end{array}$ & $1.71 *$ \\
\hline ITTERACY & $\begin{array}{c}0.33 \\
(0.114)\end{array}$ & $\begin{array}{c}0.48 \\
(0.024)\end{array}$ & -1.23 \\
\hline DEP_RATIO & $\begin{array}{l}1.14 \\
(0.17)\end{array}$ & $\begin{array}{c}1.2 \\
(0.04)\end{array}$ & -0.34 \\
\hline MARRIED & $\begin{array}{c}0.94 \\
(0.06)\end{array}$ & $\begin{array}{c}0.94 \\
(0.01)\end{array}$ & 0.1 \\
\hline HHHEAD_MALE & $\begin{array}{c}0.89 \\
(0.08)\end{array}$ & $\begin{array}{c}0.94 \\
(0.01)\end{array}$ & -0.64 \\
\hline TOL_FEXP & $\begin{array}{c}587 \\
(135)\end{array}$ & 1875 & $-2.07 * *$ \\
\hline
\end{tabular}

As noted in section 1.3, these variables are expected to be positively correlated with the probability to save and the amount saved. Also, significantly more households that save have access to market information than those that do not (Table 2). However, considerably fewer households that have savings faced a bad production season (2008/09) than those that do not have savings. There are no significant differences in the mean values of household head, male, married and living with a spouse, and the number of retailers who buy at the farm-gate among households that save and those that do not (Table 2).

\subsection{Two-Part Model Results}

Overall, the parameters in the participation model (probit) are jointly significant at the 1 percent level, with a Wald chi-square value of 40.68 (degree of freedom 11) (Table 3). This means the model is significant in explaining the probability that a household would save. Also, about 22 percent of the variation in the dependent variable - whether or not a household would save (s) - is explained by the model, with a prediction accuracy of about 96 percent. With regards to the intensity model, approximately $12.3 \%$ of the variation in the amount of savings is explained by the model. Moreover, overall the parameters in the model are jointly significant at the 1 percent level, with an F-test of 8.31 (degree of freedom 11); it means the intensity model is significant in explaining positive outcomes of savings.

\subsubsection{Participation Model (Probit) Results}

The participation model results show that number of extension contacts and access to market information have significantly positive correlations with the probability that a household will save (Table 3 ). The signs of the above variables are consistent with a priori expectations. However, contrary to a priori expectation, illiteracy and total food expenditure have significant positive correlations with the probability that a household would save.

Households that experience a higher number of extension contacts are more likely to save, holding all other factors constant, by up to $0.8 \%$. Extension service is a source of information. In particular, it can provide producers with timely and appropriate information on agricultural technologies which can help them to increase the quantity and quality of their farm yields. Higher yields can translate into higher incomes and higher savings. It has been shown by Teshome et 
al. (2013) that extension contacts has a significantly positive effect on households' savings. Similarly, producers' that have access to market information are more likely to save by up to 7.6 percent, compared to those that do not, holding all other factors constant. This is expected because households with market information can get the right prices for their buying and selling activities.

However, households with more illiterate members are more likely to save, compared to households that do not, by up to $3.5 \%$. It is possible because uneducated household heads might have learned from experience the need to save for unexpected emergencies. However, in general, educated household heads are more likely to save compared to uneducated heads (Teshome et al., 2013).

\subsubsection{Intensity Model Results}

The results of the intensity model, show that household's landholdings (bad farming season in previous years) have significantly positive (negative) effects on the expected amount saved, holding all other factors constant. The results are consistent with a priori expectations. The signs of these variables are the same as those obtained from the estimated Heckman model (Table 3). Also, the coefficients of the variables in the two-part model are close to those obtained from the Heckman model (Table 3).

Regarding marginal effects, a unit increase in households' land holdings is expected to increase the expected amount they would save by 173.7 Birr (about \$7.45). Landholding is a measure of wealth in most African countries. Also, households with more access to land can make long-term investments in their properties to increase their farm-incomes. It has been shown in other studies that landholdings have a significant positive effect on household savings (Ahmad (Ahmad et al., 2006; Schmidt-Hebbel et al., 1992). Again, households who experienced a bad production season last year are expected to decrease their amount saved by 2760 Birr (about \$119).

Table 3. Two-part Model Results

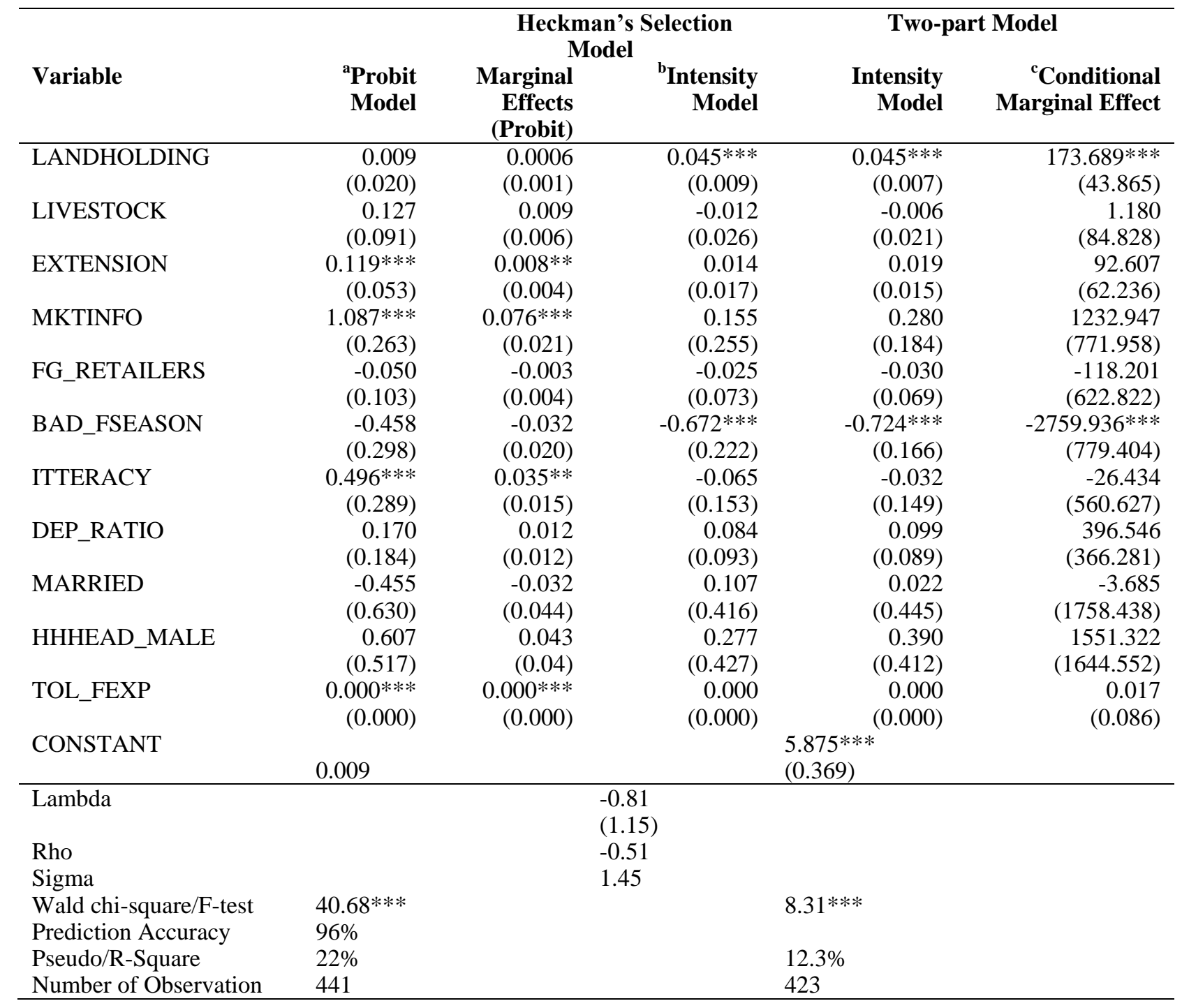


$* * *, * * *$ denotes significance at $1 \%, 5 \%$ and $10 \%$, respectively.

Robust standard errors are in parenthesis.

${ }^{a}$ Probit shows that the probit results of the Heckman Model are the same for the Two-part model.

${ }^{\mathrm{b}}$ Intensity shows the parameter estimates for the intensity model under the Heckman Model, it shows the marginal effects of the variables on the expected amount saved by the household, given that household saves.

${ }^{c}$ Conditional shows the marginal effects of the variables on the expected amount saved by the households given that the household saves.

\section{Conclusion}

This study used a two-part model to explain household's savings behavior in Ethiopia. Main findings indicate that number of extension contacts, illiteracy and access to market information have significantly positive correlations with the likelihood that a household would save. Moreover, land holdings (bad production season last year) have significantly positive (negative) effects on the expected amount of money a household would save.

The results have implications for policymakers in the public and private sectors and other relevant stakeholders who would want to encourage households to save. First, the government can intensify and extend its extension services in Ethiopia. With the right training and incentives, extension officers can teach and encourage farmers on better and more efficient ways of farming. Moreover, extension officers could be trained to provide market information to households they visit. Once these are done or improved upon, and farmers have greater access to more extension services and market information, they would be more likely to save. An important variable that might positively affect the saving behavior culture of Ethiopian households is landholding. Policies that are designed to improve access to land might enhance households' savings, holding all other factors constant. For instance, in Ethiopia, the government could initiate a viable land market backed by legislation to protect private land rights. Encouraging household members, especially heads of households, on the need for savings could also encourage saving among Ethiopian households.

\section{Acknowledgement}

I thank the Department for Agricultural and Applied Economics, Texas Tech University, for their support in conducting this research.

\section{References}

Ahmad, M. H., Atiq, Z., Alam, S., \& Butt, M. S. (2006). The impact of demography, growth and public policy on household saving: a case study of Pakistan. Asia Pacific Development Journal, 13(2), 57-72.

Anoruo, E., \& Ahmad, Y. (2001). Causal relationship between domestic savings and economic growth: Evidence from seven African countries. African Development Review, 13(2), 238-249. https://doi.org/10.1111/1467-8268.00038

Attanasio, O. P. (1999). Consåumption. Handbook of macroeconomics, 1, 741-812. https://doi.org/10.1016/S1574-0048(99)10019-3

Aryeetey, E., \& Udry, C. (2000). Saving in Sub-Saharan Africa (No. 38A). Center for International Development at Harvard University.

Belotti, F., Deb, P., Manning, W. G., \& Norton, E. C. (2015). twopm: Two-part models. Stata J, 15(1), 3-20.

Bénassy, J. P. (2011). Macroeconomic theory. Oxford University Press. https://doi.org/10.1093/acprof:osobl/9780195387711.001.0001

Browning, M., \& Lusardi, A. (1996). Household saving: Micro theories and micro facts. Journal of Economic literature, 34(4), 1797-1855.

Cameron, A. C., \& Trivedi, P. K. (2005). Microeconometrics: methods and applications: Cambridge university press. https://doi.org/10.1017/CBO9780511811241

Collins, S. M. (1991). Savings Determinants in Ten Developing Countries, in D. Bernheim and J. Shoven, eds. National Saving and Economic Performance, Chicago, Univ. of Chicago Press.

Cragg, J. G. (1971). Some statistical models for limited dependent variables with application to the demand for durable goods. Econometrica, 39, 829-844. https://doi.org/10.2307/1909582

Deaton, A. (1989). Saving in Developing Countries: Theory and Review, Proceedings of the World Bank, Annual Conference on Development Economics, Washington D.C.

Deaton, A. (2005). Franco Modigliani and the life cycle theory of consumption. 
Deaton, A. S. (1992). Saving and Income Smoothing in Cote d' Ivoire. Journal of African Economies, 1(1), 1-24. https://doi.org/10.1093/oxfordjournals.jae.a036737

Eric, A., \& Eduardo, S. (2017). Explaining Individuals' Behavior towards Their Acquisition of Students' Loan in the US. Applied Economics and Finance, 4(3), 102-110.

Hubbard, R. G., Skinner, J., \& Zeldes, S. P. (1994). Expanding the life-cycle model: Precautionary saving and public policy. The American Economic Review, 84(2), 174-179.

Keynes, J. M. (1936). The general theory of employment, interest and money. London: MacMillan.

Kibet, L. K., Mutai, B. K., Ouma, D. E., Ouma, S. A., \& Owuor, G. (2009). Determinants of household saving: Case study of smallholder farmers, entrepreneurs and teachers in rural areas of Kenya. Journal of Development and Agricultural Economics, 1(7), 137-143.

Leff, N. H. (1969). Dependency rates and savings rates. The American Economic Review, 59(5), 886-896.

Lucas, R. E. (1988). On the mechanics of economic development. Journal of monetary economics, 22(1), 3-42. https://doi.org/10.1016/0304-3932(88)90168-7

Odhiambo, N. M. (2009). Savings and economic growth in South Africa: A multivariate causality test. Journal of policy Modeling, 31(5), 708-718. https://doi.org/10.1016/j.jpolmod.2009.04.001

Quartey, P. (2008). Financial sector development, savings mobilization and poverty reduction in Ghana. Financial Development, Institutions, Growth and Poverty Reduction, 87-119. https://doi.org/10.1057/9780230594029_5

Romer, P. M. (1986). Increasing returns and long-run growth. Journal of political economy, 94(5), 1002-1037. https://doi.org/10.1086/261420

Schmidt, H. K., Webb, S. B., \& Corsetti, G. (1992). Household saving in developing countries: first cross-country evidence. The World Bank Economic Review, 6(3), 529-547. https://doi.org/10.1093/wber/6.3.529

Solow, R. M. (1956). A contribution to the theory of economic growth. The quarterly journal of economics, 70(1), 65-94. https://doi.org/10.2307/1884513

Teshome, G., Kassa, B., Emana, B., \& Haji, J. (2013). Determinants of Rural Household Savings in Ethiopia: The Case of East Hararghe Zone, Oromia Regional State.

Wooldridge, J. M. (2010). Econometric analysis of cross section and panel data: MIT press.

World Bank. (1994). Adjustment in Africa: Reforms, Results and the Road Ahead, Policy Research Report, Oxford University Press, London and New York.

World Bank. (2016). Country Data on Ethiopia. https://data.worldbank.org/country/ethiopia

World Bank. (2017). World Bank national accounts data, and OECD National Accounts data files.

\section{Copyrights}

Copyright for this article is retained by the author(s), with first publication rights granted to the journal.

This is an open-access article distributed under the terms and conditions of the Creative Commons Attribution license which permits unrestricted use, distribution, and reproduction in any medium, provided the original work is properly cited. 